\title{
The implication of chemical extraction treatments on the cell wall nanostructure of softwood
}

\author{
Karin Jungnikl · Oskar Paris · Peter Fratzl • \\ Ingo Burgert
}

Received: 5 July 2007 / Accepted: 25 September 2007/Published online: 30 October 2007

(C) Springer Science+Business Media B.V. 2007

\begin{abstract}
Spruce wood was subjected to welldefined extraction treatments with sodium chlorite $\left(\mathrm{NaClO}_{2}\right)$ for delignification, as well as with sodium hydroxide $(\mathrm{NaOH})$ at different concentrations for extraction of hemicelluloses. The corresponding changes of the macromolecular polymer assembly were investigated by small-angle X-ray scattering (SAXS). Measurements with Fourier-transform infrared (FTIR) spectroscopy and wide-angle scattering (WAXS) gave qualitative information about the effectiveness of the extraction process, while the scattering experiments provided information about the regularity and typical dimensions of the molecular structures. The scattering data indicated that delignification had only a moderate effect on the structural organisation of the cell wall, while further extraction with $\mathrm{NaOH}$ induced considerable nanostructural changes.
\end{abstract}

Keywords Cell wall nanostructure .

Extraction · Fibril aggregates ·

Picea abies [L.] Karst. .

Small-angle scattering (SAXS) $\cdot$ Softwood

K. Jungnikl $(\varangle) \cdot$ O. Paris · P. Fratzl · I. Burgert Department of Biomaterials, Max-Planck-Institute of Colloids and Interfaces, 14424 Potsdam, Germany e-mail: Karin.Jungnikl@mpikg-golm.mpg.de

\section{Introduction}

The polymer arrangement in the secondary cell wall of wood is of considerable interest, on the one hand because of the economic relevance for wood processing, on the other hand, because wood cell walls represent an impressive example of smart materials design (Niklas 1992). The question of whether and how the cellulose fibrils are organised in aggregates and their interaction with the other cell wall polymers is of particular interest in this context. One aspect, which makes the structural examination of wood cell walls difficult, is the presence of lignin and its effectiveness in protecting the other cell wall polymers from direct observation and enzymatical and chemical attacks. Even mild chemical delignification induces alterations to the original structure of both lignin and polysaccharides, producing new lignin/ carbohydrate compounds (LCCs) or even damaging the cellulose. An examination of the polysaccharides without prior delignification is-at least for softwoods-difficult due to their limited accessibility and results in an alteration of lignin (Fengel and Wegener 1984). Even preparation treatments that do not aim at removing a cell wall component might still have a structural effect (Olsson and Salmén 1992; Stoll and Fengel 1977). The course of chemical degradation, the composition of the degradation products and the resulting structures have, on the other hand, been used to develop models of the polymer assembly in the cell wall (Fengel and Wegener 1984; Lawoko 
et al. 2005; Nelson 1961; Revol and Goring 1981). Small-angle scattering (SAXS) is a useful method for the examination of plant cell walls, because it provides structural information in the size range of the polymer aggregates and requires no additional preparation. Cell wall properties like the cellulose orientation and also structural effects of moisture and chemical treatments can be observed over a statistically relevant volume of a sample (Crawshaw et al. 2002; Heyn 1955a, b; Jakob et al. 1994, 1996; Ratho and Patel 1981). Due to the complex multiphase structure of the cell walls, the evaluation of SAXS experiments however requires some simplifying assumptions.

The structure of cellulose fibrils has been examined traditionally by $\mathrm{X}$-ray diffraction and more recently by CP/MAS ${ }^{13} \mathrm{C}$ NMR spectroscopy. While diffraction provided information on the arrangement of the glucose chains in the highly ordered regions of the fibrils (O'Sullivan 1997), investigations by CP/MAS ${ }^{13} \mathrm{C}$ NMR spectroscopy revealed details about the organisation of cellulose fibrils and led to models of their interaction with the other cell wall polymers (Hult et al. 2000; Newman 1992; Wickholm et al. 1998). Typical diameters of the crystalline 'elementary cellulose fibrils' (ECF) range from approximately 2-4 nm (Ha et al. 1998; Jakob et al. 1995; Wickholm et al. 1998). The hemicelluloses are thought to act as a viscous matrix in which the fibrils are embedded and to provide a mechanically favorable 'stick-slip' mechanism when the fibre is loaded beyond elastic deformation (Fratzl et al. 2004a, b; Keckes et al. 2003). Copolymerisation experiments with bacterial cellulose (Atalla et al. 1993; Tokoh et al. 2002; Whitney et al. 1998, 1999, 1995) and studies on the polymerization of lignin (Chen and Sarkanen 2003; Lewis et al. 1999) also suggest an important role of the hemicelluloses for the structure of lignin and the formation of cellulose aggregates. In spruce wood, two kinds of hemicelluloses, xylan and glucomannan, are believed to be preferentially linked to lignin and cellulose respectively (Fahlén and Salmén 2003, 2005; Olsson and Salmén 1992; Salmén 2004, 1998). Experiments with dynamic Fourier-transform infrared (FTIR) spectroscopy have indicated interactions of glucomannan and cellulose fibrils. When load was applied on pulp fibres, glucomannan showed a response that was synchronous with the elastic response of the cellulose fibrils, which supports the assumption that it is intimately linked to the cellulose (Akerholm and Salmén 2001, 2003, 2004; Hinterstoisser et al. 2001, 2003). Based on these results, a structural model of the arrangement of the cell wall polymers was proposed (Fahlén and Salmén 2005), which suggests that a number of cellulose microfibrils surrounded by glucomannan form cellulose fibril aggregates that are embedded in a matrix of xylan and lignin. However, this study was primarily focussed on the structure of pulp fibres. On the other hand, difficulties in the observation of cellulose fibril aggregates in native, untreated cell walls have been reported (Daniel 2006) and other studies exist that report structures consisting of single fibrils in samples prepared for TEMobservations (Stoll and Fengel 1977; Deshpande et al. 2006; Persson et al. 2004).

Extraction treatments on delignified wood samples with $\mathrm{NaOH}$ allow a reasonably specific degradation of hemicelluloses (Nelson 1961). The aim of the present study is to gain further insight into the arrangement of the polymer network by drawing conclusions from the structural effects of the extraction treatments, implying a relation between the accessibility and solubility of a specific hemicellulose structure and its location in the polymer network.

\section{Experimental section}

\section{Material}

Tangential slices of $0.20-0.26 \mathrm{~mm}$ thickness were cut with a microtome from never dried spruce earlywood (Picea abies [L.] Karst.). For each series of extraction treatments, samples from one or two neighbouring slices were used to avoid artefacts resulting from natural heterogeneity. The samples were delignified using an aqueous solution of $0.3 \%$ $\mathrm{NaClO}_{2}$ buffered with acetic acid at $\mathrm{pH} 4.9$ for $4 \mathrm{~h}$ at $80{ }^{\circ} \mathrm{C}$ (Kataoka et al. 1998). On the delignified samples a successive extraction of hemicelluloses was carried out by a treatment with (A) $6 \% \mathrm{NaOH}$, (B) 6 and $8 \% \mathrm{NaOH}$ and (C) 6,8 and $10 \% \mathrm{NaOH}$ at $60{ }^{\circ} \mathrm{C}$ for $2 \mathrm{~h}$ each (Nelson 1961). The samples were washed in deionised water between and after the treatments. Therefore, during measurements, the degree of swelling was not due to the $\mathrm{NaOH}$ concentration but due to the structural changes 
induced by the treatment. To assess the formation of cellulose II during the extraction, an additional treatment at $60{ }^{\circ} \mathrm{C}$ and at $90{ }^{\circ} \mathrm{C}$ was carried out with $10 \% \mathrm{NaOH}$ for $10 \mathrm{~h}$, additional samples were prepared with the treatment at $90{ }^{\circ} \mathrm{C}$ for $1,3.5$ and 5.5 h. Alternatively, samples were treated with a 1:1 solution of $30 \% \mathrm{H}_{2} \mathrm{O}_{2}$ in glacial acetic acid for $25 \mathrm{~h}$ at $60{ }^{\circ} \mathrm{C}$. This treatment has been used as a method to extract single fibers from wood and for biomechanical studies (Burgert et al. 2005a, b; Groom et al. 2002). It removes the middle lamella between the fibers as well as the lignin and xylan in the cell wall (Burgert et al. 2005c). After all treatments the samples were washed with deionised water and stored in a refrigerator at $4-8{ }^{\circ} \mathrm{C}$.

\section{IR-spectroscopy}

IR-spectra were collected in ATR-mode from the dried samples after the X-ray measurements. Three to five spectra per sample were measured, depending on the condition of the sample. A BioRad FTS 6000 Spectrometer and an IR-Microscope (Bruker Vertex 70 equipped with a Hyperion 2000 Microscope) were used alternatively. The spectra were measured with a resolution of $4 \mathrm{~cm}^{-1}$ from 4000 to $400 \mathrm{~cm}^{-1}$ with 32 scans per measurement with the BioRad-spectrometer and from 4000 to $600 \mathrm{~cm}^{-1}$ with 128 scans per measurement with the IR-microscope, respectively. The spectra were averaged and normalised using the OPUS software. The area from 650 to $1800 \mathrm{~cm}^{-1}$ was selected as reference for the normalisation using the function 'vector normalisation'. This function normalises the spectra by the average of the absorption values 1: $\sum_{i=1}^{N P T}\left(x_{i}\right)^{2}=1$. Only relative changes in the averaged spectra were evaluated. Characteristic wavenumbers of cell wall polymer bands that were used for evaluating the effects of the treatments are listed in Table 1.

Small- and wide-angle X-ray scattering

Small-angle (SAXS) and wide-angle (WAXS) scattering experiments were carried out on a Nanostar instrument (Bruker AXS) using $\mathrm{CuK} \alpha$ radiation with a wavelength $\lambda=0.154 \mathrm{~nm}$ selected by a bent multilayer. Two-dimensional (2D) scattering patterns were collected with a position sensitive area detector (HiStar). Three different sample-detector distances of 5, 25 and $105 \mathrm{~cm}$ allowed to cover overlapping regions of the length of the scattering vector $\mathrm{q}$ from $0.2 \mathrm{~nm}^{-1}<\mathrm{q}<27 \mathrm{~nm}^{-1}$, where $\mathrm{q}=4 \pi \sin (\theta) / \lambda$ with $2 \theta$ being the scattering angle. The measurements in wet (never dried) condition were carried out using a vacuum tight sample holder with Kapton windows. The dry samples were directly placed in the high vacuum of the instrument. The $2 \mathrm{D}$ patterns were azimuthally averaged and corrected for transmission and instrument background.

\section{Interpretation of the SAXS signal}

For systems consisting of two phases which are separated by a sharp interface, Porod's law can be applied for a quantitative evaluation of the SAXS profiles (Porod 1951). The spherically averaged intensity can be written as $\mathrm{I}(\mathrm{q})=2 \pi(\Delta \rho)^{2} * \mathrm{~S} /$ $\mathrm{q}^{4}=\mathrm{P} / \mathrm{q}^{4}$ for large values of $\mathrm{q}$, where $\mathrm{S}$ is the total interface per unit volume of the two phases, $\Delta \rho=($ $\left.\rho_{\mathrm{A}}-\rho_{\mathrm{B}}\right)$ is the electron density difference or contrast between the two phases $\mathrm{A}$ and $\mathrm{B}$, and $\mathrm{P}$ is the Porod constant (Glatter and Kratky 1982), The Tparameter or mean chord length characterising a typical length scale in the two-phase system can be calculated through the relation $\mathrm{T}=4 / \pi * \tilde{\mathrm{I}} / \mathrm{P}$, where $\tilde{\mathrm{I}}$ is the integrated intensity $\tilde{\mathrm{I}}=\int \mathrm{q}^{2} \mathrm{I}(\mathrm{q}) \mathrm{dq}$. The $\mathrm{T}$ parameter is related to the chord lengths $a$ and $b$ of the two phases by $1 / \mathrm{T}=1 / \mathrm{a}+1 / \mathrm{b}$ (Glatter and Kratky 1982). The value therefore emphasises the dimensions of the phase with the smaller structures.

Lignified cell walls must be considered to consist of at least three distinct phases: the crystalline fibrils, the matrix polymers (lignin and hemicellulose) and a third phase representing either water filled or empty voids, depending on whether the sample is dry or water saturated. If one particular contrast contribution dominates the scattering, the cell wall may, with some caution, be approximated by a two-phase system. The electron densities of the individual cell wall components were estimated following the procedure described by Jakob et al. (1996). Estimates of the resulting contrasts for some important combinations are listed in Table 2. In the dry state, the contrast is dominated by the scattering of pores, voids or cracks. The dominant scattering contrast in the wet 
Table 1 Characteristic wavenumbers of cell wall polymer bands used for evaluating the effects of the treatments

\begin{tabular}{|c|c|c|c|}
\hline & Wavenumber $\left[\mathrm{cm}^{-1}\right]$ & Band assignment & Reference \\
\hline \multirow[t]{4}{*}{ Lignin } & 1510 & Aromatic skeletal vibrations & Schwanninger et al. (2004) \\
\hline & 1423 & Aromatic skeletal vibrations & Schwanninger et al. (2004) \\
\hline & 1221 & $\begin{array}{l}\mathrm{C}-\mathrm{C}, \mathrm{C}-\mathrm{O} \text { plus } \mathrm{C}=\mathrm{O} \text { stretch, } \\
\text { typical for Guiacyl units }\end{array}$ & Schwanninger et al. (2004) \\
\hline & 1140 & $\begin{array}{l}\text { Aromatic } \mathrm{C}-\mathrm{H} \text { in-plane deformation, } \\
\text { typical for Guiacyl units }\end{array}$ & Schwanninger et al. (2004) \\
\hline \multirow[t]{3}{*}{ Xylan } & 1730 & $\mathrm{C}=\mathrm{O}$ stretch, sidegroups & Åkerholm and Salmén (2004) \\
\hline & 1600 & $\mathrm{C}=\mathrm{O}$ stretch, sidegroups & Åkerholm and Salmén (2004) \\
\hline & 1245 & $\mathrm{C}=\mathrm{O}$, sidegroups & Åkerholm and Salmén (2004) \\
\hline \multirow[t]{2}{*}{ Glucomannan } & 870 & $\begin{array}{l}\text { Equatorial } \mathrm{C}(2)-\mathrm{H} \text { bond mannose residue } \\
\text { deformation }\end{array}$ & Marchessault (1962) \\
\hline & 805 & In-phase ring stretching mannose residue & Marchessault (1962) \\
\hline \multirow[t]{2}{*}{ Cellulose } & 1160 & Antisymmetric $\mathrm{C}-\mathrm{O}-\mathrm{C}$ bridge stretching & Liang and Marchessault (1959) \\
\hline & $1107(1105)$ & Antisymmetric ring stretching & $\begin{array}{l}\text { Marchessault and Liang (1960) } \\
\text { and Liang and Marchessault (1959) }\end{array}$ \\
\hline
\end{tabular}

native samples was found (Jakob et al. 1996) to emerge from crystalline cellulose fibrils vs. wet matrix polymers and from water filled pores. The effect of the chemical treatments on the contrast in the wet state was estimated on basis of literature describing properties of the chemically altered polymer matrix (Fahlén and Salmén 2003; Olsson and Salmén 1992; Åkerholm and Salmén 2004; Burgert et al. 2005c; Crawshaw et al. 2002; Deshpande et al. 2006; Hill and Papadopoulos 2001; Lindström 1986;

Teleman et al. 2001).

\section{Results}

IR-spectroscopy

The IR measurements were used to assess the effectiveness of the treatments on the samples which was a precondition for a reliable characterisation and for the interpretation of the X-ray signals. The accessibility of the cell wall has a strong influence on the effectiveness of the treatments and their specificity. Many of the references characterising the extraction methods were carried out on pulped, chipped or otherwise pre-treated samples and even here the natural variability of the cell wall composition was found to have a strong influence. Even though a quantitative evaluation of the spectra collected in ATR-mode is difficult due to the different physical condition of the samples, they provide a good basis for a semiquantitative interpretation because the contact area of the ATR-tip is sufficiently small to select comparable areas and they provide information on a cell wall volume of several $\mu \mathrm{m}$.

The lignin removal by $\mathrm{NaClO}_{2} /$ acetic acid can be observed by a reduction of the bands at 1510 ,

Table 2 Estimated values of scattering contrasts in the cell wall

\begin{tabular}{llll}
\hline Cell-wall component & $\rho\left(10^{23} \mathrm{e}^{-} / \mathrm{cm}^{3}\right)$ & Contrast agents & $\Delta \rho^{2}$ \\
\hline Cellulose & 5.1 & Cellulose vs. dry MP & 0.25 \\
Matrix polymers (MP) & $\approx 4.6$ & Cellulose/dry MP vs. pores & $>20$ \\
Water & 3.4 & Cellulose vs. MP/water & $\approx 1.0$ \\
& & Cellulose vs. water & 2.9 \\
\hline
\end{tabular}

The electron densities of lignin and hemicelluloses can only be estimated very roughly because their macromolecular structure in the native cell wall is not exactly known. They are summarised under matrix polymers (MP) with the same electron density. The value for $(\Delta \rho)^{2}$ of the matrix polymers in the wet state is estimated on the basis of a 1:1:1 ratio of lignin, hemicelluloses and water. After lignin removal, it is assumed that lignin is replaced by water 


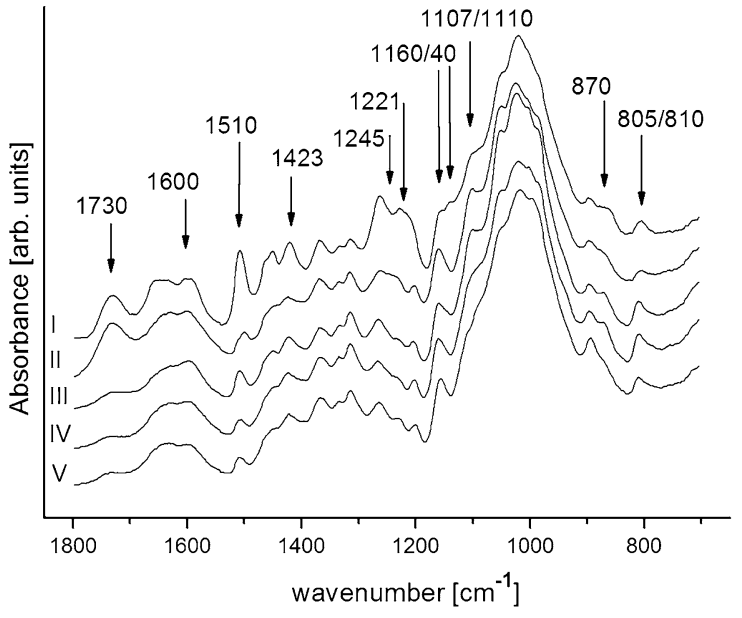

Fig. 1 IR-Spectra: (I) native, (II) delignified $\left(\mathrm{NaClO}_{2}\right)$, (III) after subsequent extraction with $6 \% \mathrm{NaOH}$, (IV) $8 \% \mathrm{NaOH}$, (V) $10 \% \mathrm{NaOH}$ for $2 \mathrm{~h}$ each. The figures were offset for clarification

$1423 \mathrm{~cm}^{-1}$ (assigned to aromatic skeletal vibrations) and other lignin related bands (e.g. 1221, $1140 \mathrm{~cm}^{-1}$ ). After the additional treatment with $\mathrm{NaOH}$, the peak at $1510 \mathrm{~cm}^{-1}$ decreased further (Fig. 1). The alkaline treatment might, however, lead to aromatic degradation products (Fengel and Wegener 1984) which makes a quantitative evaluation of the actual lignin reduction after the $\mathrm{NaOH}$ treatments on basis of the IR-spectra difficult. The removal of xylan was observed by the reduction of the bands at 1730 , 1600 and $1245 \mathrm{~cm}^{-1}$, the degradation of glucomannan was visible by the reduction of the band at $870 \mathrm{~cm}^{-1}$ and the shift and reduction of the band at $805 \mathrm{~cm}^{-1}$. The subsequent treatment of the delignified sample with 6 and $8 \% \mathrm{NaOH}$ removed the xylan. At this point, glucomannan was affected to some extent as can be seen from the shift of the peak at $805 \mathrm{~cm}^{-1}$ to around $810 \mathrm{~cm}^{-1}$ and the reduction of the peak at $870 \mathrm{~cm}^{-1}$ that is assigned to the mannose residues of glucomannan. Upon treatment with $10 \%$ $\mathrm{NaOH}$ a significant decrease of the peak at $810 \mathrm{~cm}^{-1}$ occurred and the peak at $870 \mathrm{~cm}^{-1}$ disappeared. These effects were more pronounced after treatment at $90{ }^{\circ} \mathrm{C}$ than after treatment at $60{ }^{\circ} \mathrm{C}$. The shift of the $\mathrm{C}-\mathrm{O}-\mathrm{C}$ bridge stretching band can be used as an indicator of cellulose II formation (Nelson and O'Connor 1964). In the present work, it was located at $1160 \mathrm{~cm}^{-1}$ after the delignification treatment and shifted to lower wavenumbers with increasing $\mathrm{NaOH}$ concentration. Another band that, when disappearing, is reported (Nelson and O'Connor 1964) as an indicator of cellulose II formation, is the band assigned to ring asymmetric valence vibrations positioned at $1107-1110 \mathrm{~cm}^{-1}$. It was positioned at $1105 \mathrm{~cm}^{-1}$ in the spectra after delignification. Its relative height in the spectra of the $\mathrm{NaOH}$ treated samples was in good agreement with the degree of conversion seen in the WAXS measurements. It disappeared in the spectra of the delignified samples treated with $10 \% \mathrm{NaOH}$. The shift of the $1160 \mathrm{~cm}^{-1}$ band and the flattening of the $1110 \mathrm{~cm}^{-1}$ band were coinciding with the reduction of the bands at 870 and $805 \mathrm{~cm}^{-1}$, which indicates that the formation of cellulose II was coinciding with the degradation of glucomannan, respectively its mannose residues. After $\mathrm{H}_{2} \mathrm{O}_{2}$ treatment (not shown), the peak at $805 \mathrm{~cm}^{-1}$ was still present, which indicates that glucomannan was not removed. The peak at $1427 \mathrm{~cm}^{-1}$ was related to cellulose crystallinity (Nelson and O'Connor 1964), it showed a relative increase, which is in agreement with the observation from the WAXS measurement (as described below). An increase of the $\mathrm{C}=\mathrm{O}$ bands at $1730 \mathrm{~cm}^{-1}$ and $1245 \mathrm{~cm}^{-1}$ was interpreted as a result of carbohydrate degradation.

\section{Wide-angle X-ray scattering (WAXS)}

The WAXS pattern of native spruce wood is dominated by three strong equatorial reflections from native cellulose, which are broadened due to the small microfibril diameter. Clearly observable are the 020 equatorial peak at $\mathrm{q} \approx 16 \mathrm{~nm}^{-1}$ and the 004 meridional peak $\left(\mathrm{q} \approx 25 \mathrm{~nm}^{-1}\right)$. The 110 and $1 \overline{1} 0$ reflections merge into one broad peak at around $11.5 \mathrm{~nm}^{-1}$ as long as the cellulose I crystallite structure is not disturbed severely. The rearrangement of the cellulose chains due to the interaction with $\mathrm{NaOH}$ at concentrations $>10 \%$ leads to a smearing of this peak as the two peaks shift apart, to the peak positions of cellulose II (Fengel et al. 1995). The 110 peak shifts to a lower diffraction angle (about $9 \mathrm{~nm}^{-1}$ ), the $1 \overline{1} 0$ peak shifts to about $15 \mathrm{~nm}^{-1}$ towards the 020 peak (Fig. 2).

No conversion of cellulose I into cellulose II was observed after delignification and successive treatment with 6 and $8 \% \mathrm{NaOH}$. A pronounced formation of cellulose II occurred after treatment with $10 \%$ 

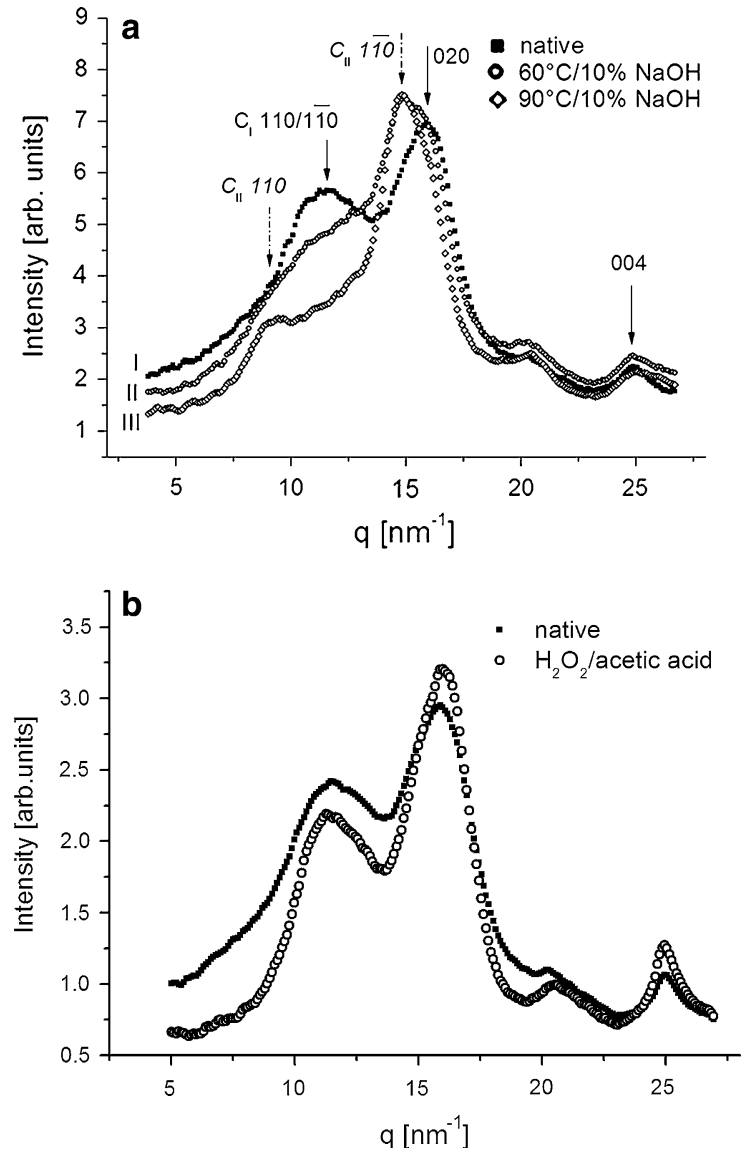

Fig. 2 WAXS: (a) Formation of cellulose II in spruce wood: (I) native, (II) delignified and treated with $10 \% \mathrm{NaOH}$ at $60{ }^{\circ} \mathrm{C}$, incomplete transformation to cellulose (II. III) $10 \%$ $\mathrm{NaOH}$ at $90{ }^{\circ} \mathrm{C}$, complete transformation. (b) Effect of $\mathrm{H}_{2} \mathrm{O}_{2}$ / acetc acid treatment on the crystallinity

$\mathrm{NaOH}$. The amount of cellulose II was the same in the samples treated with $10 \% \mathrm{NaOH}$ at $60{ }^{\circ} \mathrm{C}$ for $10 \mathrm{~h}$ and after treatment with 6,8 and $10 \% \mathrm{NaOH}$ for $2 \mathrm{~h}$ each. The conversion in the samples treated with $10 \% \mathrm{NaOH}$ at $90{ }^{\circ} \mathrm{C}$ for $10 \mathrm{~h}$ was stronger than after treatment at $60{ }^{\circ} \mathrm{C}$. It was pronounced already after $1 \mathrm{~h}$, an increase of the amount of cellulose II was still observable after 3 and $5.5 \mathrm{~h}$, but no further change occurred in the remaining $4.5 \mathrm{~h}$. The WAXS pattern of the $\mathrm{H}_{2} \mathrm{O}_{2}$ treated samples showed an increase of the peak maxima which can be interpreted as a relative (due to the degradation of matrix polymers and accessible cellulose) and/or absolute (due to crystallisation of originally non-crystalline cellulose) increase in crystallinity (Fig. 2b).
Small-angle X-ray scattering (SAXS)

Figure 3 shows a typical 2D SAXS-pattern of native wet spruce wood. The anisotropy is due to the high degree of orientation of the cellulose fibrils in the wood cell wall. For wood with a low microfibril angle as in the present case, the SAXS patterns consist of a sharp intensity streak perpendicular to the cell axis and an azimuthal average of the 2D patterns comes very close to a spherical average. In order to be able to apply standard SAXS evaluation techniques, the scattering was spherically averaged as described in Jakob et al. (1996). The modified Guinier law for rods $\left(\mathrm{I}(\mathrm{q}) \propto 1 / \mathrm{q} * \mathrm{e}^{-\mathrm{q}^{2} R_{g}^{2} / 4}\right)$ (Glatter and Kratky 1982) can be used for a quantitative evaluation of the diameter of fibrillar structures. Basic preconditions for applying this method are not given in the case of wood cell walls (2-phase model, small $\mathrm{q}\left(\mathrm{q} * \mathrm{R}_{\mathrm{g}}<1\right) \mathrm{R}_{\mathrm{g}}$ being radius of gyration). Nevertheless, the plots of the native and the $\mathrm{H}_{2} \mathrm{O}_{2}$ treated samples contained a Guinier regime that could be evaluated. Diameters of around $2.5 \mathrm{~nm}$ were found for the native samples, in good agreement with the value reported by Jakob et al. (1996). The result for the $\mathrm{H}_{2} \mathrm{O}_{2}$ treated samples was about $3.15 \mathrm{~nm}$ in the wet state and $1.75 \mathrm{~nm}$ in the dry state. The plots of the $\mathrm{H}_{2} \mathrm{O}_{2}$ treated samples display a pronounced maximum at around $\mathrm{q} 1.6 \mathrm{~nm}^{-1}$ after drying. In contrast to the native ones, the $\mathrm{H}_{2} \mathrm{O}_{2}$

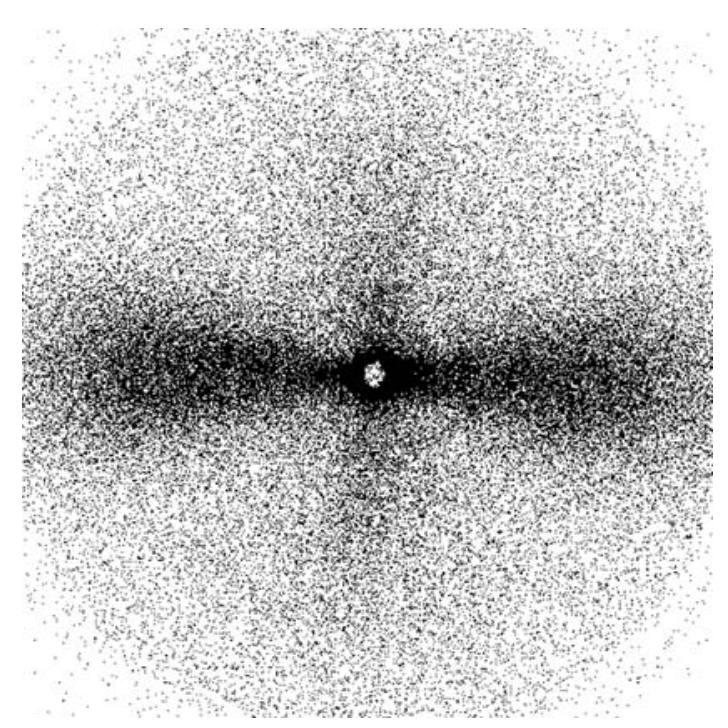

Fig. 3 Typical 2D SAXS-pattern of native spruce wood in wet condition 
Table 3 Calculated T-parameters (mean values)

\begin{tabular}{llll}
\hline & $\mathrm{T}$ (wet) $(\mathrm{nm})$ & $\mathrm{T}$ (dry) (nm) & T (dry) (nm) (fibril structure) \\
\hline Native & 2.1 & 1.8 & $1.3 \pm 0.2$ \\
$\mathrm{NaClO}_{2}$ delignified & $2.1 \pm 0.19$ & $2.2 \pm 0.35$ & $1.1 \pm 0.1$ \\
Deli. $60^{\circ} \mathrm{C} 6 \% \mathrm{NaOH}$ & 3.3 & 1.6 & $1.0 \pm 0.1$ \\
$\quad+8 \% \mathrm{NaOH}$ & 3.0 & 1.6 & $1.0 \pm 0.1$ \\
Deli. $60^{\circ} \mathrm{C} 10 \%$ & $2.7 \pm 0.14$ & $1.9 \pm 0.34$ & $1.2 \pm 0.1$ \\
Deli. $90^{\circ} \mathrm{C} 10 \%$ & $3.2 \pm 0.49$ & $2.0 \pm 0.01$ & $1.1 \pm 0.3$ \\
$\mathrm{H}_{2} \mathrm{O}_{2}$ /acetic acid & 3.9 & 1.5 & 0.9 \\
\hline
\end{tabular}

The standard deviation was only calculated where sample numbers were sufficient. The value reflects the typical length scale in the scattering phases with the dominant contrast. Due to the stronger influence of the smaller structures (see Methods section), the value in the wet condition should be more determined by the fibril dimensions, while the collapsed interspaces should be dominant for the values in the dry state

treated cell walls can be considered genuine two phase systems, the removal of the matrix polymers (lignin/xylan) leaving only the density contrast of fibrils vs. their spacing. The calculation of the Tparameter was possible for all samples, since a $\mathrm{q}^{-4}$ behaviour of the intensity (see Methods section) was found after subtraction of a constant background at large $\mathrm{q}$ values. The calculated $\mathrm{T}$-parameters are listed in Table 3.

Scattering profiles of wet and dry samples after $\mathrm{NaClO}_{2}$-delignification and subsequent alkali extraction are shown in Fig. 4. In the wet state, major changes of the SAXS profiles after the treatments were only observed at low q, while the shoulder in the $\mathrm{q}$ region of $1-2 \mathrm{~nm}^{-1}$ attributed to the fibril structure was less affected. The delignified samples showed only a slight increase of the intensity at $\mathrm{q}<1.4 \mathrm{~nm}^{-1}$ but after already a very mild $\mathrm{NaOH}$ treatment $(6 \%)$, the appearing of a new strong scattering contribution at low q lead to a pronounced change in the SAXS profiles. After treatment with $8 \%$ and $10 \% \mathrm{NaOH}$, the intensity at low q increased further and the shoulder flattened.

Two Porod regimes (i.e. a slope of -4 in the double logarithmic representation) are observable in the profiles of the dry samples. At low q, the patterns are dominated by a scattering contribution of high intensity (see Table 2) from large structures like aggregates or drying cracks $(>50 \mathrm{~nm})$. At $\mathrm{q} \approx 1-$ $2 \mathrm{~nm}^{-1}$, the scattering signal shows a shoulder which can be assumed to come mainly from the fibril structures. At very large $\mathrm{q}\left(\mathrm{q} \sim 2 \mathrm{~nm}^{-1}\right)$, the pattern is overlapped by diffuse WAXS contributions (Heyn 1955a) which lead to a deviation from the -4 power law, significantly after $\mathrm{NaOH}$ treatment. When the
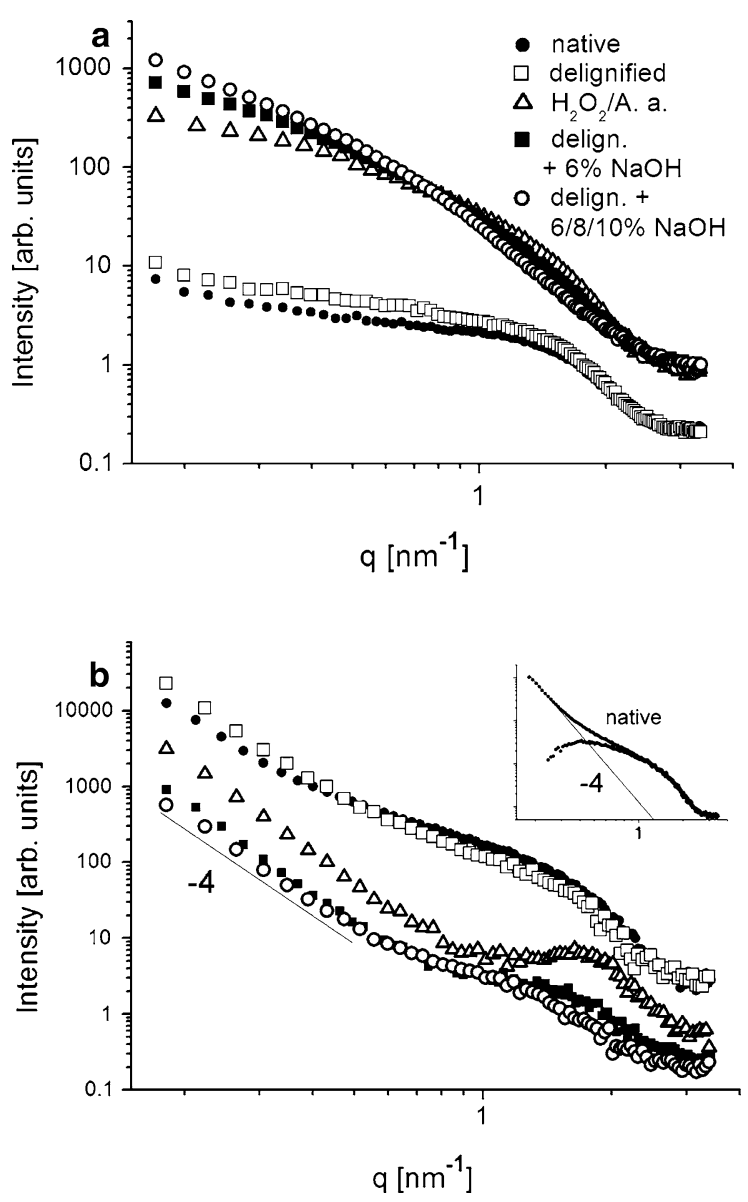

Fig. 4 SAXS: Double logarithmic plots of (a) the wet samples and (b) the dry samples. Native (full circle), delignified (empty square), $\mathrm{H}_{2} \mathrm{O}_{2}$ /acetic acid treated (triangle), delignified and treated with $6 \% \mathrm{NaOH}$ (full square) and $10 \% \mathrm{NaOH}$ (empty circle). The line indicates a $\mathrm{q}^{-4}$ power law of the scattering intensity. The insert in Fig. 4b shows the spherically averaged signal of the native sample before and after subtraction of the large scale Porod contribution 
two contributions from cracks and fibrils are separated by subtracting the $\mathrm{q}^{-4}$ contribution from the large scale structures, the T-parameter from the cellulose fibril contribution can be estimated (Table 3). This T-parameter characterises only the fibril structures and stayed approximately the same around $1.0 \mathrm{~nm}$. The value was a little higher for the native samples $(1.2 \mathrm{~nm})$ and the samples containing cellulose II $\left(1.2 \mathrm{~nm}\right.$ at $60{ }^{\circ} \mathrm{C}$ and $1.1 \mathrm{~nm}$ at $\left.90{ }^{\circ} \mathrm{C}\right)$. It is interesting to note that an increased T-parameter in the wet, swollen state was always accompanied by smaller values in the dry state, which suggests a full collapse of the structures.

\section{Discussion}

A quantitative understanding of the SAXS profiles is difficult due to the multiphase character of the cell wall, but a qualitative discussion of the changes of the $\mathrm{T}$-parameter in the wet and dry state provides insight into the structural changes. Figure 5 a gives a compilation of the experimental data, showing the change of the $\mathrm{T}$ parameter in the wet condition as a function of the chemical treatments and the polymer degradation. Figure $5 \mathrm{~b}-\mathrm{d}$ presents a schematic model of the cell-wall based on the interpretation of the SAXS data.

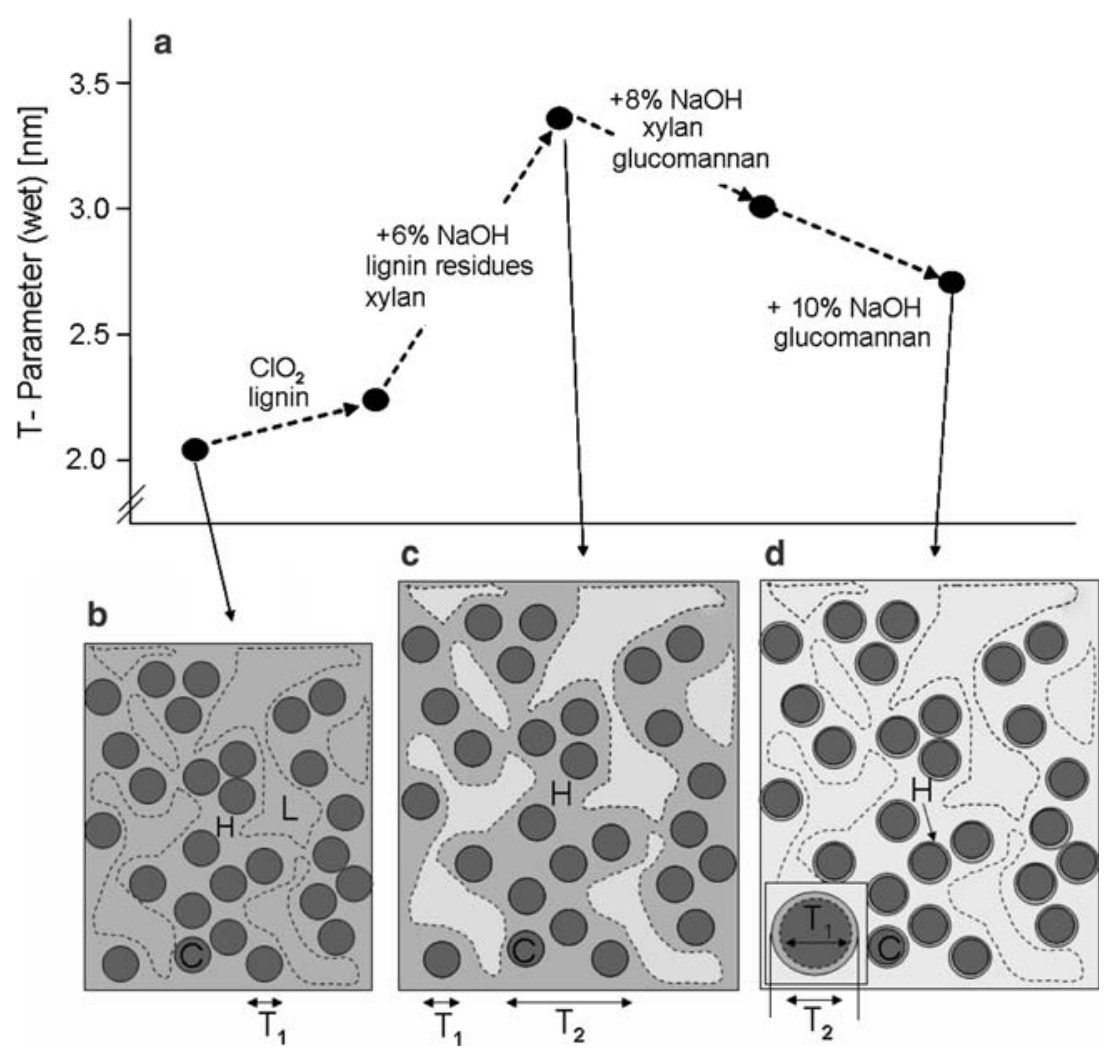

Fig. 5 Sketch of the proposed structural changes during chemical extraction of spruce wood. (a) Change of the Tparameter in wet condition as a function of the successive chemical treatment. Polymers that are degraded are mentioned with the respective treatment step. (b) Putative arrangement of cellulose fibrils (diameter characterised by $\mathrm{T}_{1}$ ) in the hemicellulose/lignin matrix, based on cell wall models suggested by Fahlén and Salmén (2005) and Jakob et al. (1996). C, H, and L denote cellulose fibrils, hemicelluloses and lignin-rich areas.
Grey scale indicates electron density. At this stage, there is practically no contrast between $\mathrm{H}$ and L. (c) Delignification and treatment with $6 \% \mathrm{NaOH}$ lead to swelling of the matrix and to the appearance of a contrast between $\mathrm{H}$ and $\mathrm{L}$ areas as well as of a new length scale $\mathrm{T}_{2}$. (d) With further extraction of hemicelluloses the remaining length scale $T_{2}$ is only due to cellulose fibrils coated with the remaining hemicellulose or increased by swelling $(\mathrm{H})$ 
For both native and delignified samples, the intensity distribution in the SAXS patterns of the wet samples is smooth and without any clear interference maxima (see Fig. 4). There is no indication of aggregates of a preferred size in the range of the measurements $(6-30 \mathrm{~nm})$, nor of an ordered distribution of the cellulose fibrils (Jakob et al. 1996). The profile shapes of native and delignified samples are similar (Fig. 4), differing only by the slight increase of intensity at low $\mathrm{q}<1.4 \mathrm{~nm}^{-1}$ after delignification, while the T-parameter remained unchanged (Table 3). A random distribution of cellulose fibrils results in a certain size distribution of the interspaces filled with lignin/hemicellulose matrix (Fig. 5b). Delignification would therefore lead to an equally broad size distribution of areas where the matrix was delignified and water adsorbed instead, resulting in the slightly higher intensity (due to the increased density contrast) in the corresponding $\mathrm{q}$ range. A pronounced change of the shape of the SAXS profile was observed after additional treatment with $6 \% \mathrm{NaOH}$ and the T-parameter increased strongly. This change was interpreted as coming from a new density contrast of the larger size scale ' $\mathrm{T}_{2}$ ' (Fig. 5c). In this treatment step the last lignin residues and parts of the xylan were removed. The better accessibility of the wider interfibrillar spaces that were probably also already more affected by the delignification leads to a preferred matrix degradation and water adsorption in these areas, leading to the new density contrast between the ' $\mathrm{H}$ ' and ' $\mathrm{L}$ ' areas. The $\mathrm{q}$ region $>1.4 \mathrm{~nm}^{-1}$ remained largely unchanged, which suggests that the cellulose fibrils were not affected at this point (Fig. 4). This is in agreement with the findings from the WAXS- and IR-measurements which also suggest that $\mathrm{NaOH}$ concentrations below $10 \%$ did not result in a structural degradation of the crystalline cellulose and that the cellulose fibrils and the associated glucomannan were still structurally intact at this point. Treatment with 8 and $10 \% \mathrm{NaOH}$ lead to a flattening of the shoulder at $1-2 \mathrm{~nm}^{-1}$ as well as to a shift of the strong low q contribution to lower q, out of the accessible range of the measurement, visible by the steepening of the SAXS profile (Fig. 4). This change of the profile and the decrease of the $\mathrm{T}$ parameter indicate that the treatments started to affect the fibril structure at this point. With progressive matrix removal, the large scale contrast ' $\mathrm{T}_{2}$ ' of the preferentially extracted ' $L$ ' areas would disappear again in favour of a structure consisting of cellulose fibrils in the remaining, more or less homogeneous, diluted matrix (Fig. 5d). Another factor contributing to the decrease of the T-parameter might be the reduction of the swelling power due to the decreasing amount of swellable hemicelluloses (i.e. their reactive sites) (Lindström 1986) resulting in an overall smaller scaled cell wall structure. The fact that the value is still higher than in the native samples can be explained by a beginning swelling of the cellulose fibrils due to the interaction with $\mathrm{NaOH}$ (Crawshaw et al. 2002) or an aggregation of hemicellulose residues on the fibril surfaces. After treatment with $10 \% \mathrm{NaOH}$, glucomannan was degraded (see IRmeasurements) and cellulose II was formed. The coinciding of these two effects is a further indication for the close association of glucomannan and cellulose (Åkerholm and Salmén 2001; Hinterstoisser et al. 2003; Olsson and Salmén 1992). At this point, the native fibril structure can be assumed to be destroyed, because the formation of cellulose II requires the mobility and reorganisation of the cellulose fibrils at the level of the individual glucose chains and their interaction with $\mathrm{NaOH}$ and water.

The measured SAXS profiles give information about a limited size range, excluding any drying cracks or aggregates larger than about $30 \mathrm{~nm}$. The Tparameters therefore represent a qualitative measure for the degree of swelling and structural collapse upon drying. The T-parameter emphasises the dimensions of the phase with the smaller structures (see Methods section). For the swollen samples, this means that the $\mathrm{T}$-parameter is presumably more determined by the fibrils than by the spaces between them. After drying, the size distribution seems to be reverse and the T-parameter more determined by the interfibrillar spaces. The value for the fibrillar structure calculated after subtraction of the -4 power law is stable, the slight differences may come from different degrees of collapse and contributions from very small fibril fractions. The $\mathrm{T}$-parameter for the whole structure gives an impression on the degree of collapse on the cell wall level. A larger T-parameter in the wet state is always accompanied by smaller values in the dry state, indicating that the structural conditions for swelling and collapse are somehow positively related. For the delignified samples, the Tparameter after drying increased slightly compared to 
the native samples, while the value for the fibrillar structure decreased (Table 3). This is in agreement with findings from investigations i.e. by adsorption methods on spruce pulp in literature (Hill and Papadopoulos 2001; Lindström 1986), which indicate that delignification leads to a stronger collapse of the polymer structure upon drying (Teleman et al. 2001) and favours the formation of wider cracks rather than of small cracks or voids where lignin was removed.

In contrast to the delignified and $\mathrm{NaOH}$ treated samples, the SAXS signals of the $\mathrm{H}_{2} \mathrm{O}_{2}$ /acetic acid treated samples indicate a structure of high regularity and uniform fibril size in the wet as well as in the dry state. In the wet state, this interpretation is supported by the Guinier analysis, in the dry state by the clear intensity maximum.

\section{Conclusion}

The nanostructural organisation of the secondary cell wall after established chemical extraction methods was studied by SAXS experiments in combination with IR-spectroscopy and WAXS. Different degrees of structural degradation were observed upon delignification and subsequent treatment with increasing concentrations of $\mathrm{NaOH}$. The course of the structural degradation observed by SAXS was interpreted on the basis of changing density contrasts and size scales (the T-parameter). The findings suggest that the cell wall is not necessarily a network of cellulose/ glucomannan aggregates of biosynthetically predefined size, but might as well be a network of elementary fibrils that are individually organized with the other polymers. A wide distribution of aggregate sizes in the native cell wall e.g. formed during the process of lignification of the S2 layer, would also produce SAXS profiles like the observed. The course of the changes of the SAXS profiles suggests that aggregates form during extraction due to a kind of 'snowball effect' initiated by the better accessibility of larger interfibrillar spaces. This interpretation is supported by the uniform fibril structure resulting from $\mathrm{H}_{2} \mathrm{O}_{2}$ /acetic acid treatment, which differs from the $\mathrm{NaOH}$ extraction e.g. by a very thorough matrix removal in just one preparation step. However, a more detailed characterisation of the $\mathrm{H}_{2} \mathrm{O}_{2}$ /acetic acid extraction would be necessary to understand the different structural effects of the two methods. The degradation of glucomannan by $\mathrm{NaOH}$ at concentrations of $10 \%$ was coinciding with the formation of cellulose II, which confirms the importance of glucomannan for the fibril structure and the close association of cellulose and glucomannan.

Acknowledgments Financial support by the FWF (Austrian Science Fund) is gratefully acknowledged. The authors thank Dr. Burgi Gierlinger for her help with the IR-measurements and valuable comments and Ingrid Zenke for her support with the X-ray investigations.

\section{References}

Åkerholm M, Salmén L (2001) Interactions between wood polymers studied by dynamic FT-IR spectroscopy. Polymer 42:963-969

Åkerholm M, Salmén L (2003) The oriented structure of lignin and its viscoelastic properties studied by static and dynamic FT-IR spectroscopy. Holzforschung 57:459-465

Åkerholm M, Salmen L (2004) Softening of wood polymers induced by moisture studied by dynamic FTIR spectroscopy. J Appl Polym Sci 94:2032-2040

Atalla RH, Hackney JM, Uhlin I, Thompson NS (1993) Hemicelluloses as structure regulators in the aggregation of native cellulose. Int J Biol Macromol 15:109-112

Burgert I, Eder M, Frühmann K, Keckes J, Fratzl P, StanzlTschegg S (2005a) Properties of chemically and mechanically isolated fibres of spruce (Picea abies [L.] Karst.). Part 3: mechanical characterisation. Holzforschung 59(3):354-357

Burgert I, Frühmann K, Keckes J, Fratzl P, Stanzl-Tschegg S (2005b) Properties of chemically and mechanically isolated fibres of spruce (Picea abies [L.] Karst.). Part 2: twisting phenomena. Holzforschung 59(2):247-251

Burgert I, Gierlinger N, Zimmermann T (2005c) Properties of chemically and mechanically isolated fibres of spruce (Picea abies [L.] Karst.). Part 1: structural and chemical characterisation. Holzforschung 59(2):240-246

Chen Y, Sarkanen S (2003) Macromolecular lignin replication: a mechanistic working hypothesis. Phytochem Rev 2: 235-255

Crawshaw J, Bras W, Mant GR, Cameron RE (2002) Simultaneous SAXS and WAXS investigations of changes in native cellulose fiber microstructure on swelling in aqueous sodium hydroxide. J Appl Polym Sci 83: 1209-1218

Daniel G (2006) WURC's impact on our understanding of wood fibre nanostructure. In: Salmén L (ed) Fifth plant biomechanics conference, Stockholm, Sweden, 2006

Deshpande AS, Burgert I, Paris O (2006) Hierarchically structured ceramics by high-precision nanoparticle casting of wood. Small 2(8-9):994-998

Fahlén J, Salmén L (2003) Cross-sectional structure of the secondary wall of wood fibers as affected by processing. J Mater Sci 38:119-126 
Fahlén J, Salmén L (2005) Pore and matrix distribution in the fiber wall revealed by atomic force microscopy and image analysis. Biomacromolecules 6:433-438

Fengel D, Wegener G (1984) Wood: chemistry, ultrastructure, reactions. Walter de Gruyter, Berlin/New York

Fengel D, Jakob H, Strobel C (1995) Influence of the alkali concentration on the formation of cellulose-II-study by X-ray-diffraction and FTIR spectroscopy. Holzforschung 49(6):505-511

Fratzl P, Burgert I, Gupta HS (2004a) On the role of interface polymers for the mechanics of natural polymeric composites. Phys Chem Chem Phys 6:5575-5579

Fratzl P, Burgert I, Keckes J (2004b) Mechanical model for the deformation of the wood cell wall. Z Metallkd 95:1-7

Glatter O, Kratky O (1982) Small angle X-ray scattering. Academic Press Inc. Ltd., London

Groom L, Mott L, Shaler S (2002) Mechanical properties of individual southern pine fibers. Part I. Determination and variability of stress-strain curves with respect to tree height and juvenility. Wood Fiber Sci 34(1):14-27

Ha M-A, Apperley DC, Evans BW, Huxham IM, Jardine WG, Vietor RJ, Reis D, Vian B, Jarvis MC (1998) Fine structure in cellulose microfibrils: NMR evidence from onion and quince. Plant J 16:183-190

Heyn ANJ (1955a) Small particle X-ray scattering by fibers, size and shape of microcrystallites. J Appl Phys 26: $519-526$

Heyn ANJ (1955b) Small particle X-ray scattering by fibers. II. Radial distribution of microcrystallites. J Appl Phys 26:1113-1120

Hill CAS, Papadopoulos AN (2001) A review of methods used to determine the size of the cell wall microvoids of wood. J Inst Wood Sci 15:337-345

Hinterstoisser B, Åkerholm M, Salmén L (2001) Effect of fiber orientation in dynamic FTIR study on native cellulose. Carbohydr Res 334:27-37

Hinterstoisser B, Åkerholm M, Salmén L (2003) Load distribution in native cellulose. Biomacromolecules 4: 1232-1237

Hult EL, Larsson PT, Iversen T (2000) A comparative CP/ MAS C-13-NMR study of cellulose structure in spruce wood and kraft pulp. Cellulose 7:35-55

Jakob HF, Fratzl P, Tschegg SE (1994) Size and arrangement of elementary cellulose fibrils in wood cells: a small-angle X-ray scattering study of Picea abies. J Struct Biol 113:13-22

Jakob HF, Fengel D, Tschegg SE, Fratzl P (1995) The elementary cellulose fibril in Picea abies: comparison of transmission electron microscopy, small-angle X-ray scattering, and wide-angle X-ray scattering. Macromolecules 28:8782-8787

Jakob HF, Tschegg SE, Fratzl P (1996) Hydration dependence of the wood-cell wall structure in Picea abies. A smallangle X-ray scattering study. Macromolecules 29: 8435-8440

Kataoka Y, Kondo T (1998) FT-IR microscopic analysis of changing cellulose crystalline structure during wood cell wall formation. Macromolecules 31:760-764

Keckes J, Burgert I, Frühmann K, Müller M, Kölln K, Hamilton M, Burghammer M, Roth SV, Stanzl-Tschegg S,
Fratzl P (2003) Cell-wall recovery after irreversible deformation of wood. Nat Mater 2:810-814

Lawoko M, Henriksson G, Gellerstedt G (2005) Structural differences between the lignin-carbohydrate complexes present in wood and in chemical pulps. Biomacromolecules 6:3467-3473

Lewis NG, Davin LB, Sarkanen S (1999) The nature and function of lignins. In: Barton DHR, Nakanishi K, MethCohn O (eds) Comprehensive Natural Products Chemistry, Vol 3, Elsevier, London

Liang CY, Marchessault RH (1959) Infrared spectra of crystalline polysaccharides.2. Native celluloses in the region from 640 to $1700 \mathrm{~cm}$.-1. J Polym Sci 39:269-278

Lindström T (1986) The porous lamellar structure of the cell wall. In: Bristow JA, Kolseth P (eds) Paper: Structure and Properties. Marcel Dekker Inc., New York

Marchessault RH (1962) Applications of infrared spectroscopy to the study of wood polysaccharides. Spectrochim Acta 18:876-876

Marchessault RH, Liang CY (1960) Infrared spectra of crystalline polysaccharides.3. Mercerized cellulose. J Polym Sci 43:71-84

Nelson R (1961) The use of holocellulose to study cellulose supermolecular structure. J Polym Sci 51:27-58

Nelson ML, O'Connor RT (1964) Relation of certain infrared bands to cellulose crystallinity and crystal lattice type. Part I. Spectra of lattice types I, II, III and of amorphous cellulose. J Appl Polym Sci 8:1311-1324

Newman RH (1992) Nuclear-magnetic-resonance study of spatial relationships between chemical-components in wood cell-walls. Holzforschung 46:205-210

Niklas KJ (1992) Plant biomechanics-an engineering approach to plant form and function. University of Chicago Press, Chicago/London

O'Sullivan AC (1997) Cellulose: the structure slowly unravels. Cellulose 4:173-207

Olsson AM, Salmén L (1992) Viscoelasticity of insitu lignin as affected by structure-softwood vs hardwood. ACS Symp Ser 489:133-143

Persson PV, Hafren J, Fogden A, Daniel G, Iversen T (2004) Silica nanocasts of wood fibers: a study of cell-wall accessibility and structure. Biomacromolecules 5: $1097-1101$

Porod G (1951) Die Röntgenkleinwinkelstreuung von dichtgepackten kolloiden Systemen. Kolloid Z and Z für Polymere 124:83-114

Ratho T, Patel A (1981) Small-angle X-ray studies on sisal fiber. J Phys D Appl Phys 14:2169-2177

Revol J-F, Goring DAI (1981) On the mechanism of the mercerization of cellulose in wood. J Appl Polym Sci 26:1275-1282

Salmén L (2004) Micromechanical understanding of the cellwall structure. C R Biol 327:873-880

Salmén L, Olsson AM (1998) Interaction between hemicelluloses, lignin and cellulose: structure-property relationships. J Pulp Paper Sci 24:99-103

Schwanninger M, Rodrigues JC, Pereira H, Hinterstoisser B (2004) Effects of short-time vibratory ball milling on the shape of FT-IR spectra of wood and cellulose. Vib Spectrosc 36:23-40 
Stoll M, Fengel D (1977) Studies on holo-cellulose and alpha-cellulose from spruce wood using cryo-ultramicrotomy.1. Structural-changes of fiber walls during delignification and alkali extraction. Wood Sci Technol 11:265-274

Teleman A, Larsson PT, Iversen T (2001) On the accessibility and structure of xylan in birch kraft pulp. Cellulose 8:209-215

Tokoh C, Takabe K, Sugiyama J, Fujita M (2002) Cellulose synthesized by Acetobacter xylinum in the presence of plant cell wall polysaccharides. Cellulose 9:65-74

Whitney SEG, Brigham JE, Darke AH, Reid JSG, Gidley IMJ (1995) In vitro assembly of cellulose/xyloglucan networks: ultrastructural and molecular aspects. Plant J 8:491-504

Whitney SEC, Brigham JE, Darke AH, Reid JSG, Gidley MJ (1998) Structural aspects of the interaction of mannanbased polysaccharides with bacterial cellulose. Carbohydr Res 307:299-309

Whitney SEC, Gothard MGE, Mitchell JT, Gidley MJ (1999) Roles of cellulose and xyloglucan in determining the mechanical properties of primary plant cell walls. Plant Physiol 121:657-663

Wickholm K, Larsson PT, Iversen T (1998) Assignment of non-crystalline forms in cellulose I by CP/MAS ${ }^{13} \mathrm{C}$ NMR spectroscopy. Carbohydr Res 312:123-129 